\title{
Knowledge of Student's Understanding and The Effect on Instructional Strategies: a Case of Two Novice Mathematics Teachers
}

\author{
Masduki $^{2)}$, Suwarsono $^{2)}$, Mega Teguh Budiarto ${ }^{3)}$ \\ ${ }^{1)}$ Universitas Muhammadiyah Surakarta, \\ Doctoral Student in Mathematics Education, State University of Surabaya (UNESA) \\ ${ }^{2}$ Sanata Dharma University, Yogyakarta \\ ${ }^{3)}$ State University of Surabaya (UNESA) \\ Corresponding author: masduki@ums.ac.id
}

\begin{abstract}
Pedagogical content knowledge plays a role in learning in classroom. The study aims to 1) analyze the teachers' knowledge of the students' errors and difficulties in solving linear equations and 2) describe the instructional strategies used by teachers to reduce their errors and difficulties. The subjects were two novice teachers who have taught the Junior High School $7^{\text {th }}$ grade students with different math abilities for two years. The data collection was conducted by open questionnaire and interview. The results showed that both teachers have knowledge of students' errors and difficulties in solving linear equations. However, the teacher's learning strategies in helping students reduce students' errors and difficulties were different from one another. It can be concluded that the teacher's knowledge of the students' errors and difficulties can belp teachers determine the appropriate learning strategies to present a learning subject matter.
\end{abstract}

Keywords: pedagogical content knowledge, students' errors and difficulties, teachers' strategies

\section{Introduction}

Teaching is not an easy job. Teachers need a variety of knowledge to be able to teach well. As stated by NCTM (2000), "teaching mathematics well is a complex endeavor, and there are no easy recipes" (p.17). Furthermore, NCTM (2000) states that for an effective learning process, a teacher must have in-depth knowledge and understanding of the content, curriculum, student characteristics, learning methods, and classroom management. A comprehensive study of the knowledge of teachers has been discussed by Shulman (1986). In his study of an effective teaching process, Shulman stated that there are three kinds of the teachers' knowledge: content knowledge (CK), pedagogical content knowledge (PCK), and curricular knowledge. PCK is defined by Shulman (1986) as "content knowledge that embodies the aspects of content most germane to its teachability" (p.6). Furthermore, Shulman (1987) developed the PCK definition as "representing the blending of content and pedagogy into an understanding of how particular topics, problems, or issues are organized, represented, and adapted to the diverse interests and abilities of learners, and presented for instruction" (p. 8).

In addition to the knowledge to present the content, PCK includes knowledge of students' understanding, the purpose of learning content, understanding students' 
difficulties in learning topics, conceptions and misconceptions, knowledge of learning strategies, and student backgrounds that influence learning such as culture, and physical environment (Cochran, DeRuiter, \& King, 1993; Grossman, 1989; Magnusson, Krajcik, \& Borko, 1999; Marks, 1990; Shulman, 1986; Smith \& Neale, 1991; Tamir, 1988). Grossman \& Richert (1988) defines the knowledge of students' understanding as knowledge of the conceptions and misconceptions of specific subject-matter, initial understanding and students' knowledge of subjects, and student interest in the content. An et. al (2004) identified student misconceptions as a sub-category of one of the PCK components.

Some researchers have identified several subcategories of knowledge of students' understanding. Shulman (1986) stated that the knowledge of what causes an easy or difficult subject-matter for students as one of the characteristics of PCK, but he does not state it as a subcategory of knowledge of student's understanding. Furthermore, some scholars state that knowledge of students' errors on the subject-matter (Marks, 1990; Smith \& Neale, 1991), student interest in subject-matter (Grossman \& Richert, 1988; Park \& Chen, 2012; Park \& Steve Oliver, 2008), motivation (Cochran et al., 1993; Park \& Chen, 2012; Park \& Steve Oliver, 2008), knowledge of prerequisite content (Magnusson et al. 1999), and knowledge of student difficulties in studying subjects (Magnusson et al., 1999; Park \& Chen, 2012; Park \& Oliver, 2008) are part of knowledge of students' understanding.

In junior high school, students learn algebra by using variables to represent a quantity, solve an equation that contains variables, and represent the word problem in the form of algebraic expression. There are differences in the course of algebra in primary and junior high schools. In primary school, learning algebra focuses on the arithmetic operation by using numbers, but in junior high school, the course of algebra involves the variables in its operations. At this stage, students takes the cognitive transition of mathematical thinking from arithmetic to algebraic thinking (Filloy \& Rojano, 1989; Warren, 2003). In other words, the student's conception of mathematical operations has changed from numbers to variables (Filloy \& Rojano, 1989). Sometimes, the transition process does not work well. It causes the cognitive gap, the inability of students to perform operations using variables (Herscovics \& Linchevski, 1994; Linchevski \& Herscovics, 1996). As a result, students have difficulty in solving algebraic problems as linear equations of one variable.

In his study of 49 junior high school students, Papaieronymou (2007) concluded that students had difficulty in distinguishing algebraic forms from linear equations. The students assume that algebraic forms and linear equations are the similar expression. Nonetheless, they have no difficulty in manipulating or simplifying algebraic forms and solving linear equations. Magruder (2012) identified three difficulties of junior high school students in solving algebraic equations, i.e. understanding of symbols or variables, meaning of sign $=$ (equal to), and emphasizing procedural knowledge without conceptual understanding. Brizuela \& Schliemann (2004) explained the lack of students' understanding in solving algebraic problems. According to their research, the difficulties of students in learning algebra are due to low ability in arithmetic concepts and its application on algebra. Similarly, in the study of 51 Indonesian students in understanding algebra, Jupri, Drijvers, \& Heuvel-Panhuizen (2014) concluded that students have difficulty in the process of mathematization, changing the word problem in mathematics expressions or symbols. Other difficulties include understanding algebraic expressions and application of arithmetic operations to algebra, and sign = (equal to) and variable.

The focus of the paper is on discussing the teachers' knowledge of the students' understanding of their errors and difficulties in studying linier equations of one variable. 
It will also discuss the teachers' instructional strategy to teach algebra to them with different math ability.

\section{Research Method}

The research was conducted in Sukoharjo regency, Central Java Province, Indonesia. The subjects were two junior high school mathematics teachers (Joko and Ema) who have taught the different private Junior High Schools $7^{\text {th }}$ grade students. They have the same education background as a bachelor degree of mathematics education. Joko has taught the students who are low in math ability, but Ema has taught those who are high in math ability.

The data was collected by using the interview and open questionnaires, containing four problems of linear equations of one variable. These were used for exploring their understanding of the student's errors. They were asked to write errors that are generally made by the students in solving the given problems. Furthermore, the interview was deeply intended to find out their understanding of the students' errors and their difficulties in solving linear equations of one variable. In addition, it was conducted to explore strategies used by teachers to teach algebra, especially solving linear equations of one variable.

\section{Finding and Discussion}

'The teachers' answers to the students' errors in solving four questions of linear equations of one variable are reported in Table below.

Table

Teachers' answers to the student's errors

\begin{tabular}{|c|c|c|c|}
\hline Number & Problem & Ema's answer & Joko's answer \\
\hline 1 & $x+10=47$ & $\begin{array}{l}x=47+10 \\
x=57\end{array}$ & $\begin{array}{l}x=47+10 \\
x=57\end{array}$ \\
\hline 2 & $4 x-1=0$ & $\begin{array}{l}4 x=1 \\
x=1:-4 \\
x=-\frac{1}{4}\end{array}$ & $\begin{array}{l}4 x=1 \\
x=1-4\end{array}$ \\
\hline 3 & $2-4 x=3$ & $\begin{array}{l}-4 x=3-2 \\
-4 x=1 \\
x=\frac{1}{4}\end{array}$ & $\begin{array}{l}4 x=3-2 \\
4 x=1 \\
x=1-4\end{array}$ \\
\hline 4 & $2+\frac{x}{4}=5$ & $\begin{array}{l}\left(2+\frac{x}{4}=5\right) \times 4 \\
1+x=20\end{array}$ & $\begin{array}{l}\frac{x}{4}=5-2 \\
x=3\end{array}$ \\
\hline
\end{tabular}

In Table 1, there are Joko's and Ema's similar answers relating to the student's error in solving the first problem. According to the two teachers, the students mostly made misconceptions in solving $x+10=47$. The answer to the first problem should be $x=47-10=37$, but most of them answered $x=47+10=57$. Based on the interview with the two teachers, the students were confusing with the concept of equality $(=)$ in solving an equation. They did not understand every manipulation in an equation that the left side must be equal to the right one. This means that if the left side is added or subtracted by a number or variable, and so is the right side. 
Furthermore, on the second and third problem, both the teachers gave different answers regarding the students' errors. According to Ema, the students had been able to understand the procedure to solve linear equations that contain coefficients on the variables, but they made misconceptions in solving equations. They understand that the concept of the operation of division on the linear equation is the same as the addition or subtraction. So, the divisor becomes -4 in the second answer and 4 in the third one.

On the other hand, Joko wrote down the similar answer to the student's errors on the second and third problems. According to him, the students did not understand the procedure to solve an equation that contains coefficients on the variable. They only understood the procedure on the addition or subtraction to solve the given problems. So, the students' answers to the linear equations problem of $4 x=1$ is $x=1-4$.

The fourth problem is the linear equation where the variable $x$ contains the coefficient of rational numbers. Ema stated that her students already understood the procedure to solve the given problem. The equation on the fourth problem was multiplied by the denominator of the rational number of the given problem, but some students made errors in multiplication. They did not multiply each term in the equation by the number of denominator. Frequently, they did not the calculations accurately. Otherwise, Joko stated that his students solved the fourth problem in a same way as the use of the procedure to solve the first one. They did not understand how to operate the equations with rational numbers. Thus, most of them ignored coefficients on variables in the form of rational numbers in solving linear equations.

Both of the teachers stated that the lack of the students' understanding of the rules on the arithmetic operation is the most influential factors that cause the emergence of the students' errors in solving algebraic problems especially linear equations. Further, based on the interviews, algebra is one of difficult subject matter to teach the junior high school students. The teachers have difficulty in determining strategies for teaching variables, constants, algebraic operations, and procedure to solve linear equations which can be understood by the students. The main difficulties relate to the differences in algebraic concepts which the students learn in primary and junior high school. Algebra in primary school emphasizes on operations with numbers or arithmetic, but the concept of algebra in junior high school focuses on operations with variables or abstract symbols.

Both of the teachers have the differences instructional strategies for teaching algebra especially in solving linear equations of one variable. Ema stated that for teaching the solution to the problem of linear equations which were understandable by students, she emphasized on conceptual learning. She taught the principle of equality on an equation before explaining the procedure to solve linear equations problems. To solve the first problem, for example, in the beginning she taught by using the principle of equality, i.e. each term (left and right sides) of equations is added with -10 . Thus, the first problem becomes $x+10-10=47-10$. Therefore the solution is $x=37$. The students could solve the equation more easily if they understood conceptually in the first. In addition, the students would also ask the teacher if there are not conceptual-based procedures, such as "move-segment" operation often used by teachers to solve linear equations problems.

In contrast, Joko had difficulty in teaching conceptually in solving linear equations by students. He stated that they had difficulties in understanding the solution by using the equality principle of an equation. They are more likely a quick and practical procedure to solve a problem. Although they did not understand conceptually how the procedure is organized, for example a "move-segment" operation. According Joko, the students prefer remembering or memorizing to understanding the procedure. As a result, he emphasized 
on providing exercises so that the students will be get accustomed to solving various types of problems.

In his study of ten primary and nine junior prospective school teachers, Ball (1988) found that teachers with deep understanding of subjects matter emphasized on conceptual learning. Likewise, Borko \& Putnam (1996) in his study stated that teachers with deep-subject matter knowledge emphasized conceptual understanding, problem solving, and inquiry in teaching the subject matter. Conversely, the teachers with low understanding tended to emphasize on procedures, rules, facts, and sometimes forgot the important concepts and its relationships in learning. Rollnick, Bennett, Rhemtula, Dharsey, \& Ndlovu (2008) in the researches of science teachers in South Africa also found that the teachers with low conceptual understanding of subject matter solely relied on procedures or algorithms in learning and did not develop different teaching strategies. Conversely, the teachers who understood both concepts and procedures were able to use innovative learning approaches. They could integrate pedagogical knowledge, context, and understanding of students with subject-matter knowledge. They could also develop appropriate learning strategies in the instructional topics. Similarly, Widjaja \& Stacey (2009) showed that the teachers who were low in their understanding of concepts, relationships, and concrete models of fractions and decimals tended to teach the subject matter as mere arithmetic skills. In contrast, the teachers who have understood the meaning and concept of fractions and decimals could conceptually explain the subject matter to the students.

The results of the research showed that the instructional strategies used by teachers are not only influenced by the teacher's understanding of the subject matters, but the students' mathematical ability also affects their instructional strategies. The teachers who teach the students with middle or high math ability emphasize on the conceptual learning. They can find the procedural solutions in accordance with the rules or nature of the subject matter. Conversely, the teachers who teach the students with low math ability are difficult to implement a learning process conceptually. The students tend to understand the subject matter by remembering or memorizing. As a result, the teachers focus on giving exercises to the students in order to solve various types of problems.

The research results are strengthened by some previous studies of the differences in the students' ability and the teachers' instructional strategies. Shulman (1986) argued that understanding the students' concepts and pre-conceptions with different backgrounds and ages ask teachers to have the knowledge of determining appropriate instructional strategies so that students can understand a subject matter well. Furthermore, Park \& Oliver (2008a) states that in the effective implementation of PCK, a teacher must understand the knowledge of students' conceptions of subject matter topics, learning difficulties, motivation, abilities, learning styles, interests, and needs. Van Garderen (2008) in his research of teacher learning practice in solving mathematics word problems states that a teacher needs to have knowledge of instructional strategies to teach problem solving to students who have learning difficulties. Some researchers have also pointed out that the use of different instructional strategies is due to the students with different cognitive abilities (Krawec, 2014; Mancl, Miller, \& Kennedy, 2012; Garderen, Scheuermann, \& Jackson, 2013; Garderen, 2008).

\section{Conclusion}

The teachers with the same educational background and teaching experience are similar to understanding the students' errors and difficulties in learning a subject matter. They can identify the errors commonly made by students in solving linear equations of one variable. They can explain the factors that lead the students to make them. The 
students' mathematics ability is one of the factors that can influence the difference of instructional strategies used by teachers in teaching the solving of linear equations of one variable. The teachers who teach the students with high mathematics ability can implement conceptual learning that explains any solution by using principles or procedures that are in accordance with the rules. Conversely, the teachers who teach the students with low mathematics ability emphasize on giving exercises to solve various types of problems. The students prefer remembering or memorizing to understanding the procedure. Thus, it can be concluded that students' mathematical ability have an impact on instructional strategies used by teachers to teach to the students.

\section{Acknowledgement}

The paper is the preliminary research of the authors' dissertation about teachers pedagogical content knowledge in junior high school. We would like to thank the Ministry of Research, Technology, and Higher Education, Indonesia who has funded the author to take doctoral program at graduate school of mathematics education, Surabaya State University (UNESA). Additionally, We wish also to thank the Universitas Muhammadiyah Surakarta that had allowed the author to take the program. We also thank the teachers for their participation in the research.

\section{References}

An, S., Kulm, G., \& Wu, Z. (2004). The pedagogical content knowledge of middle school, mathematics teachers in China and the U.S. Journal of Mathematics Teacher Education, 7, 145-172.

Ball, D. L. (1988). Knowledge and reasoning in mathematical pedagogy: Examining what prospective teachers bring to teacher education. Unpublished Doctoral Dissertation. Michigan State Univesity, East Lansing. https://doi.org/10.1086/461626

Borko, H., \& Putnam, R. T. (1996). Learning to Teach. In D. C. Berliner \& R. C. Calfee (Eds.), Handbook of Educational Psychology (pp. 673-708). New York: Macmillan.

Brizuela, B., \& Schliemann, A. (2004). Ten-Year-Old Students Solving Linear Equations. For the Learning of Mathematics, 24(2), 33-40.

Cochran, K. F., DeRuiter, J. A., \& King, R. A. (1993). Pedagogical Content Knowing: An Integrative Model for Teaching Preparation. Journal of Teacher Education, 44(4), 263 272.

Filloy, E., \& Rojano, T. (1989). Solving Equations : the Transition from Arithmetic to Algebra, 2(June), 19-26.

Grossman, P. L. (1989). A Study in Contrast: Sources of Pedagogical Content Knowledge for Secondary English. Journal of Teacher Education, 40(5), 24-31. https://doi.org/10.1177/002248718904000504

Grossman, P. L., \& Richert, A. E. (1988). Unacknowledged knowledge growth: A reexamination of the effects of teacher education. Teaching and Teacher Education, 4(1), 53-62. https://doi.org/10.1016/0742-051X(88)90024-8

Herscovics, N., \& Linchevski, L. (1994). A cognitive gap between arithmetic and algebra 1, 2. Educationa Studies in Mathematics, 27, 59-78.

Jupri, A., Drijvers, P., \& Heuvel-Panhuizen, M. van den. (2014). Difficulties in initial algebra learning in Indonesia. Mathematics Education Research Journal. https://doi.org/10.1007/s13394-013-0097-0

Krawec, J. L. (2014). Problem Representation and Mathematical Problem Solving of Students of Varying Math Ability. Journal of Learning Disabilities, 47(2), 103-115. https://doi.org/10.1177/0022219412436976

Linchevski, L., \& Herscovics, N. (1996). Crossing The Cognitive Gap Between 
Arithmetic and Algebra: Operating on the Unknown in the Context of Equations. Educational Studies in Mathematics, 30, 39-65.

Magnusson, S., Krajcik, J., \& Borko, H. (1999). Nature, sources, and development of pedagogical content knowledge for science teaching. In J. Gess-Newsome \& G. Lederman (Eds.), Examining pedagogical content knowledge: The construct and its implications for Science Education (pp. 95-132). Dordrecht, Netherland: Kluwer Academic. https://doi.org/10.1007/0-306-47217-1_4

Magruder, R. L. (2012). Solving Linear Equations: A Comparison of Concrete and Virtual Manipulatives in Middle School Mathematics. University of Kentucky, US. Retrieved from uknowledge.uky.edu/edc_etds/2

Mancl, D. B., Miller, S. P., \& Kennedy, M. (2012). Using the concrete-representationalabstract sequence with integrated strategy instruction to teach subtraction with regrouping to students with learning disabilities. Learning Disabilities Research and Practice, 27(4), 152-166. https://doi.org/10.1111/j.1540-5826.2012.00363.x

Marks, R. (1990). Pedagogical Content Knowledge: From a Mathematical Case to a Modified Conception. Journal of Teacher Education, 41(3), 3-11. https://doi.org/10.1177/002248719004100302

Miles, B. M., \& Huberman, A. M. (1994). Qualitative Data Analysis (2nd Editio). California: Sage Publications.

NCTM. (2000). Principles and Standards for School Mathematics. (J. Carpenter \& S. Gorg, Eds.). Reston, VA: The Natioanal Council of Teachers of Mathematics.

Papaieronymou, I. (2007). Student Difficulties in Understanding The Difference Between Algebraic Expressions and The Concept of Linear Equations. In D. Pitta - Pantazi \& G. Philippou (Eds.), Proceedings of the Fifth Congress of the European Society for Research in Mathematics Education 22 - 26 February 2007 (pp. 934-943). Larnaca, Cyprus: Department of Education, University of Cyprus.

Park, S., \& Chen, Y. C. (2012). Mapping out the integration of the components of pedagogical content knowledge (PCK): Examples from high school biology classrooms. Journal of Research in Science Teaching, 49(7), 922-941. https://doi.org/10.1002/tea.21022

Park, S., \& Oliver, J. S. (2008). Revisiting the conceptualisation of pedagogical content knowledge (PCK): PCK as a conceptual tool to understand teachers as professionals. Research in Science Education, 38(3), 261-284. https://doi.org/10.1007/s11165-007-9049-6

Park, S., \& Steve Oliver, J. (2008). National Board Certification (NBC) as a catalyst for teachers' learning about teaching: The effects of the NBC process on candidate teachers' PCK development. Journal of Research in Science Teaching. https://doi.org/10.1002/tea.20234

Rollnick, M., Bennett, J., Rhemtula, M., Dharsey, N., \& Ndlovu, T. (2008). The place of subject matter knowledge in pedagogical content knowledge: A case study of South African teachers teaching the amount of substance and chemical equilibrium. International Journal of Science Education, 30(10), 1365-1387. https://doi.org/10.1080/09500690802187025

Shulman, L. S. (1986). Those Who Understand: Knowledge Growth in Teaching. Educational Researcher, 15(2), 4-14. Retrieved from http://www.jstor.org/stable/1175860

Shulman, L. S. (1987). Knowledge and Teaching: Foundations of the New Reform. Harvard Educational Review, 57(1), 1-21. https://doi.org/10.1007/SpringerReference_17273

Smith, D. C., \& Neale, D. C. (1991). The construction of subject-matter knowledge in 
primary science teaching. Advances in Research on Teaching, 2(I), 187-243. https://doi.org/10.1016/0742-051x(89)90015-2

Tamir, P. (1988). Subject Matter and Related Pedagogical in Teacher Education. Teaching \& Teacher Education, 4(2), 99-110.

van Garderen, D. (2008). Middle School Special Education Teachers' Instructional Practices for Solving Mathematical Word Problems: An Exploratory Study. Teacher Education and Special Education, 31(2), 132-144. https://doi.org/10.1177/088840640803100206

van Garderen, D., Scheuermann, A., \& Jackson, C. (2013). Examining How Students With Diverse Abilities Use Diagrams to Solve Mathematics Word Problems. Learning Disability Quarterly, 36(3), 145-160. https://doi.org/10.1177/0731948712438558

Warren, E. (2003). The Role of Arithmetic Structure in the Transition from Arithmetic to Algebra. Mathematics Education Research Journal, 15(2), 122-137.

Widjaja, W., \& Stacey, K. (2009). Growth of pre-service teachers' knowledge and teaching ideas about decimals and fractions: The case of Vivi. Crossing Divides: Proceedings of the 32nd Annual Conference of the Mathematics Education Research Group of Australasia, 2(2001), 587-594. 